\title{
SYNTHESIS OF $\%$ - AND $\beta$-GLYCOSIDES CONTAINING SPIN LABELS, AS PROBES FOR STUDIES OF CARBOHYDRATE-PROTEIN INTERACTION
}

Nike R. Plessas and Irwin J. Goldstein

Department of Biological Chemistry, Box 034, University of Michigan, Ann Arbor, Michigan 48109 (U.S.A.)

(Received June 19th, 1980; accepted for publication, September 24th, 1980)

ABSTRACT

Nitroxide spin-labeled $\boldsymbol{\xi}$-D-glycopyranosides were synthesized in good yield and in a highly stereoselective manner by reaction of per- $O$-benzyl- $\alpha$-D-glycopyranosyl bromides with 2,2,6,6-tetramethyl-4-piperidinol under the bromide ion-catalyzed conditions devised by Lemieux et al. After hydrogenolysis, the deblocked intermediates were oxidized to give the desired, spin-labeled $\alpha$-D-glycopyranosides. Nitroxide spin-labeled $\beta$-D-glycopyranosides, as well as a $\beta$-maltoside, were synthesized by standard methods. The synthesis is also described of 2-amino-2-deoxy-D-glucose and -D-galactose derivatives having a spin label at $\mathrm{C}-2$, and of the spin-labeled compound 1-[4-( $\beta$-D-galactopyranosyloxy)phenyl $]-3-(2,2,6,6$-tetramethylpiperidin-l-oxyl4-yl)-2-thiourea.

\section{INTRODUCTION}

Spin labels have been used for studying conformational changes in biological macromolecules, and the structure and function of membranes. Although many reagents suitable for the spin-labeling of proteins and lipids are available ${ }^{1,2}$, there has not been much recent progress in the synthesis of spin-labeled carbohydrates that can be used as probes for protein-carbohydrate interactions. A few spin-labeled carbohydrates have been synthesized. These include 2,2,6,6-tetramethylpiperidin-1oxyl-4-yl $\beta$-D-galactoside ${ }^{3}, 2,2,5,5$-tetramethylpyrrolidin-1-oxyl-3-ylmethyl $\beta$-chitobioside $^{*}$, the 4-amino-2,2,6,6-tetramethylpiperidin-1-oxyl derivative of sialic acid in soluble and cell-surface glycoproteins, and covalent, nitroxide spin-labeled carbohydrates prepared via s-triazine residues ${ }^{6}$. The electron paramagnetic resonance of spin-labeled glycosides could yield valuable information about the environment of the active site of carbohydrate-binding proteins, and we describe here various nitroxide spin-labeled glycosides. The spin-labeled $\%$-D-glycosides were synthesized under the bromide ion-catalyzed conditions described by Lemieux et al. ${ }^{7}$ for the synthesis of $\ell$-D-glycopyranosides. The synthesis of spin-labeled $\beta$-glycopyranosides is rather straightforward. The synthesis of 14 and 15, having the spin label at C-2, and that of 13 , is also described. 
RESLLTS AND DISCUSSION

Spin-labeled o-D-glycoppranosides. - The synthetic route originally attempted for the synthesis of nitroxide spin-labeled $\alpha$-D-glycopyranosides ( 2 and 3 ) involved the reaction of tetra- $O$-benzyl-st-D-glucopyranosyl bromide with 2,2,6,6-tetramethylpiperidin-1-oxyl, to give the spin-labeled, per- $O$-benzylated $\alpha$-D-glycoside 1 , followed by catalytic hydrogenolysis to give the desired, nitroxide spin-labeled 0 -D-glycopyranoside. However, it was found that nitroxides are readily reduced to secondary amines during the catalytic hydrogenolysis. When the per- $O$-benzylated, spin-labeled

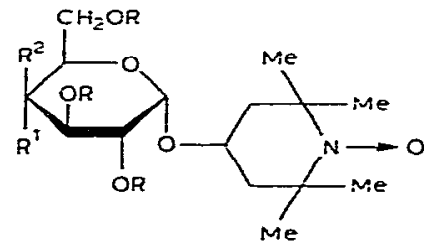

$1 \mathrm{R}=\mathrm{CH}_{2} \mathrm{Pn}, \mathrm{R}^{\mathrm{i}}=\mathrm{H}, \mathrm{R}^{2}=\mathrm{OCH}_{2} \mathrm{Ph}$

$2 R=R^{i}=H, R^{2}=O H$

$3 R=H \cdot R^{\top}=O H, R^{2}=H$

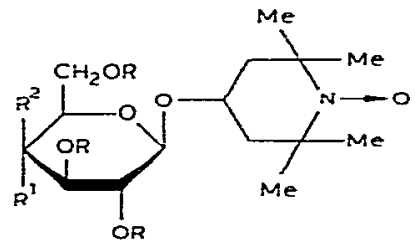

a $R=H \cdot R^{:}=O H \cdot R^{2}=H$

$9 R=A C \cdot R^{2}=O A C \cdot R^{2}=H$

$10 R=R^{\prime}=H \cdot R^{2}=O H$

$11 R=A C \cdot R^{2}=H \cdot R^{2}=O A C$

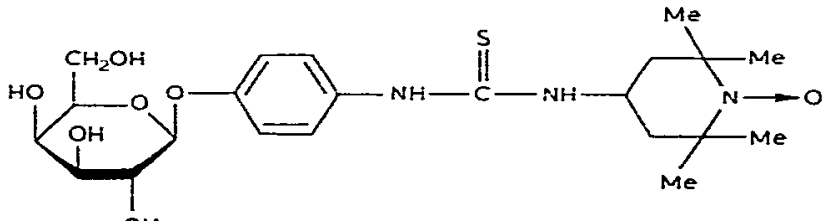

13

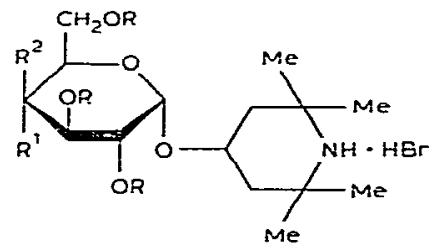

$4 \mathrm{R}=\mathrm{CH}_{2} \mathrm{Ph} \cdot \mathrm{R}^{\mathrm{i}}=\mathrm{H} \cdot \mathrm{R}^{2}=\mathrm{OCH}_{2} \mathrm{Ph}$

$5 R=R^{1}=H \cdot R^{2}=O H$

$\sigma R=C H_{2} P n, R^{\prime}=O O_{2} H_{2} P_{1} R^{2}=H$

$7 R=H \cdot R^{2}=O H \cdot R^{2}=H$

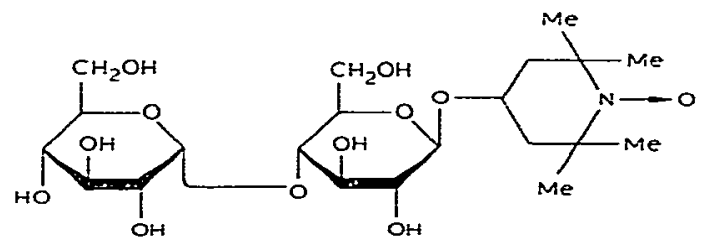

12 
$g-\mathrm{D}-$ galactopyranoside 1 was catalytically hydrogenated in the presence of palladiumon-carbon, the deblocked and reduced compound 5 was obtained.

Accordingly, for the synthesis of nitroxide spin-labeled $x$-D-glycopyranosides,

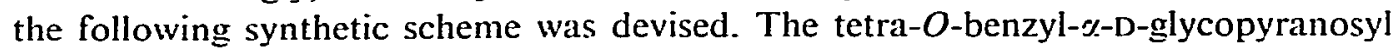
bromide was treated with 2,2,6,6-tetramethyl-4-piperidinol in the presence of tetraethylammonium bromide and $N, N$-diisopropylethylamine at room temperature in tie dark. Examination of the mixture by thin-layer chromatography (t.l.c.) revealed that the reaction was complete within $48 \mathrm{~h}$; however, a reaction time of 3 days was used. Because these glycopyranosyl bromides are highly prone to decomposition, they should be prepared at $-34^{\circ}$ immediately prior to use. A reaction time of $25 \mathrm{~min}$ is required for the preparation of tetra-O-benzyl- $x$-D-galactopyranosyl bromide, and $1 \mathrm{~h}$ for tetra- $O$-benzyl- $-\mathrm{-D}$-glucopyranosyl bromide. The per- $O$-benzylated $\alpha-\mathrm{D}$ glycopyranosides (4 and 6 ) were isolated as the hydrobromide salts, which can either be used directly for the following steps or be converted into their (more-stable) hydrochloride salts. The reactions proceeded in a highly stereospecific manner, giving better than $98 \%$ of the $\%$ anomers. The ${ }^{1} H-n . m . r$. spectra were in agreement with the structures assigned.

The per- $O$-benzylated $\alpha$-D-glycopyranosides (4 and 6 ) were deblocked by catalytic hydrogenolysis, to yield the corresponding amine hydrobromide salts. 5 and 7. Conversion into their hydrochloride salts gave samples that were analytically pure. Of all the catalysts tested, the Pearlman catalyst (palladium hydroxide on carbon ) was found to be the most effective. The reaction time, monitored by t.l.c., was 12-24 h.

Oxidation of the deblocked $x$-D-glycopyranosides 5 and 7 with hydrogen peroxide and sodium tungstate for 3-4 days in the dark afforded the desired nitroxide spin-labeled $\%$-D-glycopyranosides, 2 and 3 , as orange crystals.

To avoid decomposition of the nitroxide spin-labeled glycopyranosides, all reactions, as well as column-chromatographic purifications, were conducted in the dark. When pure and crystalline, spin-labeled glycopyranosides appear to be more stable in the dark.

Spin-labeled $\beta$-D-glycopyranosides. - For synthesis of the nitroxide spin-labeled $\beta$-D-glycopyranosides 8 and 10 , the corresponding tetra- $O$-acetyl- $\alpha$-D-glycosyl bromide and 2,2,6,6-tetramethylpiperidin-1-oxyl were allowed to react in ethanol-free chloroform, using several different catalysts for the condensation. In all cases, some orthoester was formed, and the ratio of glycoside to orthoester is very sensitive to changes in the conditions used for the condensation step. The best conditions found for the formation of $\beta$-D-glycosides involve the use either of $(a) \mathrm{Ag}_{2} \mathrm{CO}_{3}$ in ethanolfree chloroform containing a trace of iodine for $18 \mathrm{~h}$ at room temperature, or $(b)$ $\mathrm{Hg}(\mathrm{CN})_{2}$ in dry nitromethane. Condensation using $\mathrm{Hg}(\mathrm{CN})_{2}$, and $\mathrm{N}, \mathrm{N}$-dimethylformamide as the solvent, gave the orthoester in high yield.

The per- $O$-acetylated $\beta$-D-glycosides $(9$ and 11 ) were $O$-deacetylated in the standard way with methanolic sodium methoxide, to yield the desired nitroxide spin-labeled $\beta$-D-glycopyranosides ( 8 and 10).

The spin-labeled $\beta$-maltoside (12) was synthesized by condensing hepta- $O$ - 
acetylmaltosyl bromide with 2.2,6,6-tetramethylpiperidin-1-oxyl in ethanol-free chloroform in the presence of silver carbonate and a trace of iodine as catalyst. The purified, per- $O$-acetylated $\beta$-maltoside. isolated as a red syrup, was $O$-deacetylated, to give the desired spin-labeled $\beta$-maltoside (12).

Amino glycosides having spin labels at C-2. - Compounds 14 and 15 were synthesized by heating (under reflux) the corresponding methyl 2-amino-2-deoxy- $x-\mathrm{D}-$ glycopyranosides and 4-isothiocyanato-2,2,6,6-tetramethylpiperidin-1-oxyl in ethanol. After purification by column chromatography, the desired spin-labeled compounds (14 and 15) were obtained as yellow crystals in $\sim 60 \%$ yield.

Compound 13 was prepared by refluxing $p$-aminophenyl $\beta$-D-galactopyranoside with 4-isothiocyanato-2,2,6,6-tetramethylpiperidin-1-oxyl. Upon purification by column chromatography, compound 13 was isolated as an orange solid in $65 \%$ yield. $H_{y}$ drolysis of spin-labeled $\alpha-$ and $\beta$-D-glycoplranosides with $\alpha$ - and $\beta$-D-galactosidases. - The spin-labeled glycopyranosides were incubated with $\alpha$ - or $\beta$-D-galactosidase at $37^{\circ}$, and aliquots were spotted on t.l.c. plates at various time-intervals. The reaction products were detected with aniline spray (aniline and diphenylamine, in acetone), as this reagent does not develop the citrate buffer used in the reaction.

Hydrolysis of spin-labeled $\approx$-D-galactosides to D-galactose and the spin label was complete within $12 \mathrm{~h}$, in agreement with the assigned structures. In the case of $\beta$-D-galactopyranosides, complete hydrolysis was accomplished with $\beta$-D-galactosidase.

\section{EXPERIMENTAL}

General methocts. - Evaporations were conducted under diminished pressure at $25^{\circ}$ in a rotary evaporator. Melting points are uncorrected. T.l.c. was performed on precoated plates of silica gel G-60 (Brinkmann Instruments, Inc.); compounds were detected with a spray containing $5 \%$ each of ammonium molybdate, phosphoric acid, and sulfuric acid, followed by heating the plates for $10 \mathrm{~min}$ at $140^{\circ}$. Alternatively, plates were sprayed with $1 \%$ potassium permanganate in $10 \%$ sodium carbonate; the developing solvents were as specified. Silica gel $60(0.063-0.2 \mathrm{~mm}$ particle size. 70-230 mesh), used for all column chromatography, was supplied by Brinkmann Instruments. Molecular sieve was activated by heating for $12 \mathrm{~h}$ at $150^{\circ}$ before use. $\Lambda$ nhydrous dichloromethane was prepared by distilling from phosphorus pentaoxide, and storing over molecular sieve $4 \mathrm{~A}$. Before use, chloroform was dried over molecular sieve $4 \mathrm{~A}$, and passed through a column packed with reagent-grade alumina. All catalytic hydrogenations were performed at atmospheric pressure, using palladium hydroxide on carbon (the Pearlman catalyst), supplied by Aldrich Chemical Company. 2,2,6,6-Tetramethyl-4-piperidinol, tetraethylammonium bromide, and $N, N$-diisopropylethylanine were purchased from Aldrich Chemical Company. 4-Amino2,2,6,6-tetramethylpiperidine was obtained from the Eastman Kodak Co. 2,3,4,6Tetra- $O$-benzyl- $\alpha$-D-glucopyranose was purchased from Pfanstiehl Laboratories, Inc.

Tetra-O-benz!l- $\%$-D-glucopyranosyl bromide. - 2,3,4,6-Tetra- $O$-benzyl- $x$-Dglucose was converted into crystalline tetra- $O$-benzyl-D-glucopyranosyl $p$-nitrobenzo- 
ate by the procedure described by Glaudemans and Fletcher ${ }^{8}$. Although the anomers can be separated by recrystallization, the $\alpha, \beta$ mixture was found suitable for subsequent reactions. Ishikawa and Fletcher ${ }^{9}$ described the conversion of tetra- $O$-benzyl- $\varkappa$ D-glucopyranosyl $p$-nitrobenzoate into tetra- $O$-benzyl- $s$-D-glucopyranosyl bromide. Because the compound is highly unstable, it was prepared just prior to each use, as follows. To a solution of dry tetra- $O$-benzyl-D-glucopyranosyl $p$-nitrobenzoate $(3.6 \mathrm{~g})$ in dry dichloromethane $(30 \mathrm{~mL})$ cooled to $-35^{\circ}$ was added dry dichloromethane $(15 \mathrm{~mL})$ presaturated with hydrogen bromide at $0^{\circ}$, and the mixture was stirred for $\mathrm{l} h$ at $-35^{\circ}$. The precipitated $p$-nitrobenzoic acid was filtered off, and the filtrate was successively washed rapidly with cold water $(2 \times 200 \mathrm{~mL})$ and saturated sodium hydrogencarbonate $(1 \times 200 \mathrm{~mL})$, dried in the cold (sodium sulfate), and the suspension filtered (molecular sieve). The cold solution was concentrated to a small volume to give pure glycosyl bromide, as checked by t.l.c. with $3: 7$ ethyl acetate-hexane $\left(R_{\mathrm{F}} 0.5\right)$.

Tetra-O-benzyl- $\alpha$-D-galactopyranosyl bromide. - Crystalline 2.3,4,6-tetra-Obenzyl- $\xi_{-}-\mathrm{D}$-galactose was synthesized from methyl 2,3,4,6-tetra- $O$-benzyl- $\ell_{-}$-D-galactopyranoside by adopting the method described for tetra- $O$-benzyl- $f_{-}-\mathrm{D}$-glucopyranose ${ }^{8}$. The syrup was purified by column chromatography, with $50: 15: 1$ chloroform-isooctane-methanol as the developing solvent, and crystallized from ether-petroleum ether. The syrup was converted into $2,3,4,6$-tetra- $O$-benzyl- $\beta$-D-galactopyranosyl $p$-nitrobenzoate ${ }^{8,10}$, and the resulting solid was recrystallized from ether-ethanolpetroleum ether. It had m.p. 105-106 ${ }^{\circ}$, and gave a single spot in t.l.c. with 200:60:I chloroform-isooctane-methanol $\left(R_{\mathrm{F}} 0.3\right)$.

The ester was converted into the glycosyl bromide as described for the synthesis of tetra- $O$-benzyl- $g$-D-glucopyranosyl bromide. except that the reaction time wats $25 \mathrm{~min}$. As the compound is highly susceptible to decomposition. it was prepared immediately before use. It gave a single spot in t.l.c. with $3: 7$ ethyl acetate-hexane $\left(R_{\mathrm{F}} 0.4\right)$.

4-Hydroxy-2,2,6,6-tetramethylpiperidin-1-oxy - To a solution of 2.2,6.6tetramethyl-4-piperidinol $(3 \mathrm{~g}, 19.1 \mathrm{mmol})$ in water $(40 \mathrm{~mL})$ were added, with stirring, $30 \%$ hydrogen peroxide $(4 \mathrm{~mL})$, sodium tungstate $(0.2 \mathrm{~g}, 0.6 \mathrm{mmol})$ and Trilon $\mathrm{B}$ (EDTA, tetrasodium salt; $0.2 \mathrm{~g}$ ). The red solution was kept for 5 days at room temperature, saturated with potassium carbonate, repeatedly extracted with ether $(250 \mathrm{~mL}$ ), and the extracts dried (potassium carbonate), and evaporated to dryness. The residue crystallized from $2: 1$ ether-hexane, to give the title compound in $85 \%$ yield as orange crystals, m.p. $68-69^{\circ}$ (lit. ${ }^{11}$ m.p. $71.5^{\circ}$ ); it migrated as a single component in t.l.c. in 25: I chloroform-ethanol, $R_{\mathrm{F}} 0.8$; in $3: 7$ ethyl acetate-hexane, $R_{\mathrm{F}} 0.2$. 2,2,6,6-Tetramethylpiperidin-1-o.y $1-4-y /$ s-D-galactoplranoside (2). - (a) By. glycosylation of 4-hydroxy-2,2,6,6-tetramethy/piperidin-I-oxyl with retra-O-benz-y-gD-galactopyranosyl bromide to give 2,2,6,6-tetramethylpiperidin-1-oxyl-4-yl tetra-Obenzy/-s-D-galactopyranoside (1). To a mixture of 4-hydroxy-2,2,6,6-tetramethylpiperidin-l-oxyl $(1.2 \mathrm{~g}, 1 \mathrm{mmol})$, tetraethylammonium bromide $(0.42 \mathrm{~g}, 2 \mathrm{mmol})$, $N, N$-diisopropylethylamine $(0.13 \mathrm{~g}, 1 \mathrm{mmol})$, and molecular sieve $(2 \mathrm{~g})$ in dichloro- 
methane $(10 \mathrm{~mL})$ was added tetra-O-benzyl- $x$-D-galactopyranosyl bromide ( $1.2 \mathrm{~g}$, $2 \mathrm{mmol}$ ), with stirring, and the mixture, protected from moisture, was stirred in the dark for $18 \mathrm{~h}$ at room temperature. The molecular sieves were filtered off, and the filtrate, diluted with dichloromethane, was successively washed with water, cold dilute acid, sodium hydrogencarbonate solution. and water, dried (sodium sulfate), and evaporated to a red syrup which was purified by column chromatography using 3:7 ethyl acetate-hexane as the solvent. The pure product solidified on standing in the cold, and, on recrystallization from ether-petroleum ether, yielded 1 as pink crystals (77\% yield). m.p. $73-74^{\circ}$. It gave a single, u.v.-positive spot in t.l.c. using 3:7 thyl acetate-liexane $\left(R_{\mathrm{F}} 0.5\right)$ as the developing solvent.

Anal. Calc. for $\mathrm{C}_{43} \mathrm{H}_{52} \mathrm{NO}_{7}: \mathrm{C}, 74.26 ; \mathrm{H}, 7.50: \mathrm{N}, 2.02$. Found: $\mathrm{C}, 74.13$; $\mathrm{H}, 7.50 ; \mathrm{N}, 2.00$.

(b) By glycosylation of 2,2,6.6-tetramethy/-4-piperidinol to give 2,2,6,6-tetra-

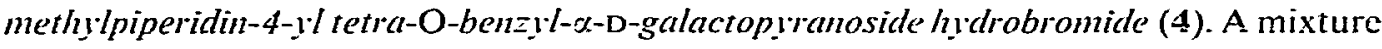
of tetra-O-benzyl- $x$-D-galactopyranosyl bromide (1.2 g, $2 \mathrm{mmol}), 2,2,6,6$-tetramethyl4-piperidinol $(0.16 \mathrm{~g}, 1 \mathrm{mmol}), N, N$-diisopropylethylamine $(0.13 \mathrm{~g}$, I mmol), tetraethylammonium bromide $(0.42 \mathrm{~g}, 2 \mathrm{mmol})$, and molecular sieve $(2 \mathrm{~g})$ in dichloromethane $(10 \mathrm{~mL})$ was stirred for 2 days at room temperature, the molecular sieve was filtered off, and the filtrate diluted with dichloromethane, washed with water, dried (sodium sulfate), and evaporated to a syrup which was purified by column chromatography with $10: 3: 1$ chloroform-isooctane-methanol as the eluant. The product, isolated as the hydrobromide salt in $\$ 3.7 \%$ yield, crystallized from ethanolpetroleum ether, and could be used as such for the oxidation step. It was chromatographically homogencous $(9: 6: 1: 3$ butanol-acetic acid-water-cther $) . R_{\mathrm{F}} \quad 0.8$; 29:6:0.6 chloroform-methanol-water, $R_{F}=0.7$.

Conversion into its hydrochloride salt yielded crystals. A solution of 4 in dry dichloromethane was acidified with dry, methanolic hydrogen chloride, and evaporated. and the resulting syrup crystallized. The crystals were filtered off, washed with ether, and recrystallized from ethanol: m.p. 228-230

Anal. Calc. for $\mathrm{C}_{43} \mathrm{H}_{5+} \mathrm{ClNO}_{6} \cdot \mathrm{H}_{2} \mathrm{O}: \mathrm{C}, 70.32 ; \mathrm{H}, 7.68 ; \mathrm{Cl}, 4.80 ; \mathrm{N}, 1.90$. Found: $\mathrm{C}, 69.88 ; \mathrm{H}, 7.20 ; \mathrm{Cl}, 5.05: \mathrm{N}, 2.02$.

Hydrogenolysis of per-O-benzylated glycosides. Hydrogenolysis of both 2,2,6,6tetramethylpiperidin-1-oxyl-4-yl tetra- $O$-benzyl- $x$-D-galactopyranoside (1) and 2,2,6,6tetramethylpiperidin-4-yl tetra-O-benzyl- $x$-D-galactopyranoside (4) gave 2,2,6,6tetramethylpiperidin-4-yl $x$-D-galactopyranoside (5). The hydrogenolysis of compound 4 is described. To a $1 \%$ solution of per- $O$-benzylated glycoside 4 in methanol was added an equal amount of the Pearlman catalyst, and the compound was hydrogenolyzed for $20 \mathrm{~h}$ at atmospheric pressurc and room temperaturc, with stirring. The suspension was filtered, and the filtrate was evaporated to a syrup which, treated with ethanol-ether, gave amorphous, hygroscopic material in $95 \%$ yield. The ${ }^{2} \mathrm{H}-\mathrm{n} . \mathrm{m} . \mathrm{r}$. spectrum was in agreement with the structure assigned. An analytical sample was obtained by converting $\mathbf{5}$ into its hydrcchloride salt. A methanolic solution of $\mathbf{5}$ was acidified with dry, methanolic hydrogen chloride, evaporated to dryness, and 
the solid extracted with ether: an amorphous, hygroscopic material was obtained from ethanol-ether.

Anal. Calc. for $\mathrm{C}_{15} \mathrm{H}_{30} \mathrm{CINO}_{6}: \mathrm{C}, 50.63 ; \mathrm{H}, 8.50: \mathrm{Cl}, 9.96: \mathrm{N}, 3.94$. Found: C, 50.22: $\mathrm{H}, 8.37 ; \mathrm{Cl}, 9.45 ; \mathrm{N}, 3.74$.

Oxidation of deblocked glycosides. To a solution of 2,2,6,6-tetramethylpiperidin4-yl $\%$-D-galactopyranoside hydrobromide $(5 ; 100 \mathrm{mg}, 0.25 \mathrm{mmol})$ in water $(5 \mathrm{~mL})$ were added $30 \%$ hydrogen peroxide $(1 \mathrm{~mL})$, sodium tungstate $(50 \mathrm{mg})$, and Trilon $\mathrm{B}$ $(50 \mathrm{mg})$. The orange solution was kept in the dark for 4 days, the hydrogen peroxide was decomposed with catalase (bovine liver, Cal BioChem-Behring Corp.), and the mixture evaporated to dryncss several times with ethanol. Compound 2 was extracted from the salts with methanol, and the extract evaporated; the red syrup resulting was further purified by chromatography on a column $(1 \times 49 \mathrm{~cm})$ of silica, with 29:10:1 chloroform- methanol-water as the eluant, yielding a syrup that, from cold ethanol-ether, gave pink crystals in $60 \%$ yield, m.p. 174-176 . It gave a single, u.v.positive spot in t.l.c. (29:10: 1 chloroform-methanol-water), $R_{\mathrm{F}} 0.45$.

Anal. Calc. for $\mathrm{C}_{15} \mathrm{H}_{28} \mathrm{NO}_{7}: \mathrm{C}, 53.88 ; \mathrm{H}, 8.44: \mathrm{N}, 4.19$. Found: $\mathrm{C}, 53.90$; H. 8.43: N, 4.15 .

2,2,6,6-Tetramethylpiperidin-l-o.:yl-4-y/ o-D-glucopyranoside (3). - The reaction of tetra-O-benzyl- $\alpha$-D-glucopyranosyl bromide with 2,2,6,6-tetramethyl-4piperidinol gave an $88.4 \%$ yield of crystalline 2,2,6,6-tetramethylpiperidin-4-yl tetra$O$-benzyl-a-D-glucopyranoside hydrobromide (6). Recrystallization from ethanolpetroleum ether yielded an analytical sample, m.p. 183-185 .

Anal. Calc. for $\mathrm{C}_{43} \mathrm{H}_{54} \mathrm{BrNO}_{6}: \mathrm{C}, 67.90 ; \mathrm{H}, 7.15 ; \mathrm{N}, 1.84$. Found: $\mathrm{C}, 67.40$; $\mathrm{H}, 7.04: \mathrm{N}, 1.86$.

Hydrogenolysis provided an $83 \%$ yield of crystalline 2,2,6,6-tetramethylpiperidin-4-yl $\alpha$-D-glucopyranoside hydrobromide (7). Conversion into its hydrochloride salt, and recrystallization thereof from ethanol-ether, gave a hygroscopic sample, m.p. 221-223․

Anal. Calc. for $\mathrm{C}_{15} \mathrm{H}_{30} \mathrm{ClNO}_{6} \cdot \mathrm{H}_{2} \mathrm{O}: \mathrm{C}, 48.18 ; \mathrm{H}, 8.62 ; \mathrm{Cl}, 9.50 ; \mathrm{N}, 3.70$. Found: $\mathrm{C}, 47.98 ; \mathrm{H}, 8.02 ; \mathrm{Cl}, 10.06 ; \mathrm{N}, 3.60$.

The oxidation procecded in $58 \%$ yield, to provide a light-orange, crystalline product that was recrystallized from ethanol; m.p. $164-165^{\circ}$; t.l.c. in $29: 10: 1$ chloroform-methanol- $\mathrm{H}_{2} \mathrm{O}, R_{\mathrm{F}} 0.5$.

Anal. Calc. for $\mathrm{C}_{15} \mathrm{H}_{28} \mathrm{NO}_{7} \cdot \mathrm{H}_{2} \mathrm{O}: \mathrm{C}, 51.12 ; \mathrm{H}, 8.50 ; \mathrm{N}, 3.97$. Found: $\mathrm{C}, 51.29$; H, $8.01 ; \mathrm{N}, 4.06$.

2.2,6,6-Tetramethylpiperidin-1-oxyl-4-yl $\beta$-D-glucopyranoside (8). - A solution of tetra- $O$-acetyl- $\alpha-\mathrm{D}$-glucopyranosyl bromide ${ }^{13}(2 \mathrm{~g}, 4.9 \mathrm{mmol})$ in dry, ethanolfree chloroform $(5 \mathrm{~mL})$ was added to a stirred mixture of silver carbonate ( $1.6 \mathrm{~g}$, $5.8 \mathrm{mmol}$ ), iodine (50 mg), molecular sieve 4A (5 g), 4-hydroxy-2,2,6,6-tetramethylpiperidin-1-oxyl ( $0.95 \mathrm{~g}, 5.5 \mathrm{mmol})$, and dry, ethanol-free chloroform ( $20 \mathrm{~mL})$. The mixture was stirred in the dark for $18 \mathrm{~h}$, and filtered through Celite, and the filtrate was washed with water $(100 \mathrm{~mL})$, dried, and evaporated to a red syrup. Chromatography on a column $(19 \times 1 \mathrm{~cm})$ with $4: 1$ dichloromethane-ether as developing 
solvent gave a red syrup which solidified from ether. It gave a single spot in t.l.c. with $4: 1$ dichloroethane-ether as the developing solvent $\left(R_{\mathrm{F}} 0.3\right)$.

A solution of the per- $O$-acetyl glycuside 9 in anhydrous methanol $(3 \mathrm{~mL})$ was cooled, and freshly prepared in sodium methoxide was added until the solution was basic to litmus paper. The solution was kept in the cold for $12 \mathrm{~h}$, evaporated to a red syrup, and the deacetylated compound purified by column chromatography, with $29: 10: 1$ chloroform-methanol-water as the developing solvent. The fractions having $R_{\mathrm{F}} 0.7$ were combined, and evaporated, giving a red syrup ( $21 \%$ overall yield) which, on trituration with ether, gave amorphous material.

Anal. Calc. for $\mathrm{C}_{15} \mathrm{H}_{28} \mathrm{NO}_{7}: \mathrm{C}, 53.88 ; \mathrm{H}, 8.44 ; \mathrm{N}, 4.19$. Found: $\mathrm{C}, 53.20$ : $\mathrm{H}, 8.21: \mathrm{N}, 4.03$.

2,2,6,6-Tetramethylpiperidin-1-o.y 1 -4-y $\% \quad \beta$-D-galactopiranoside (10). - A mixture of tetra- $O$-acetyl- $\beta$-D-galactopyranosyl bromide ${ }^{14}(2.2 \mathrm{~g}, 5.4 \mathrm{mmol})$, 4hydroxy-2,2,6.6-tetramethylpiperidin-l-oxyl (1.2 g, $6.9 \mathrm{mmol})$, mercuric cyanide (1.5 g. $6.0 \mathrm{mmol}$ ), and freshly distilled and dried (magnesium sulfate) nitromethane $(20 \mathrm{~mL}$ ) was stirred for $18 \mathrm{~h}$. The suspension was filtered through Celite, and the filtrate was evaporated to a red syrup. A solution of the syrup in chloroform was washed well with water, dried, and evaporated to a red syrup which was chromatographed with 100:30:3 chloroform-isooctane-methanol as the developing solvent. The combined fractions having $R_{\mathrm{F}} 0.3$ gave pink crystals $(0.7 \mathrm{~g}, 26 \%$ yield) from ether-petroleum ether. Deacetylation of the per- $O$-acetyl $D$-galactoside 11 with sodium methoxide in dry methanol gave compound $\mathbf{1 0}$ as a red syrup which was purified by column chromatography with $29: 10: 1$ chloroform-methanol-water as the eluant. The fractions having $R_{\mathrm{F}} 0.65$ were combined, and evaporated to a red syrup which solidined on trituration with ether, to yield an amorphous, red material in $17 \%$ yield.

Anal. Calc. for $\mathrm{C}_{15} \mathrm{H}_{28} \mathrm{NO}_{7}: \mathrm{C}, 53.88 ; \mathrm{H}, 8.44 ; \mathrm{N}, 4.19$. Found: $\mathrm{C}, 53.92$; $H, S .41 ; N, 4.13$.

2,2,6,6-Tetramethyl-4-piperidin-1-o.xyl-4-yll $\beta$-maltoside (12). - Hepta-Oacetylmaltosyl bromide was prepared from octa- $O$-acetyl- $\beta$-maltose ${ }^{15}$ by treatment with hydrogen bromide in acetic acid ${ }^{14}$. A mixture of this bromide ( $1.4 \mathrm{~g}, 2.04 \mathrm{mmol}$ ), 4-hydroxy-2,2,6,6-tetramethylpiperidin-1-oxyl (0.45 g, $2.6 \mathrm{mmol})$, silver carbonate $(3.0 \mathrm{~g}, 10 \mathrm{mmol})$. iodine $(50 \mathrm{mg})$, and molecular sieve $(5 \mathrm{~g})$ in dry, ethanol-free chloroform ( $25 \mathrm{~mL}$ ) was stirred in the dark for $18 \mathrm{~h}$, filtered, and the filtrate washed with water. dried, and evaporated to a red syrup which was purified by column chromatography with 100:30:3 chloroform-isooctane-methanol as the eluant. The fractions having $R_{F} 0.2$ were combined. and evaporated to a red syrup (17\% yield).

The per- $O$-acetylated maltoside was deacetylated with sodium methoxide in the usual way, and purified by column chromatography with 30:4:1 chloroformmethanol-water as the eluant. The fractions having $R_{\mathrm{F}} 0.4$ were combined, and evaporated to a syrup which solidified from ether to give a light-orange, amorphous material ( $55 \%$ yield).

Anal. Calc. for $\mathrm{C}_{21} \mathrm{H}_{38} \mathrm{NO}_{12} \cdot \mathrm{H}_{2} \mathrm{O}: \mathrm{C}, 49.02 ; \mathrm{H} .7 .83: \mathrm{N}, 2.72$. Found: $\mathrm{C}$, $49.07 ; H, 7.65 ; N, 2.48$. 
4-Isothiocyanato-2,2,6,6-tetramethylpiperidin-1-o.y. - 4-Amino-2,2,6.6-tetramethylpiperidine was acetylated ${ }^{12}$ (yield $95 \%$ ). The resulting 4-acctanido-2,2.6.6tetramethylpiperidine was treated with hydrogen peroxide in the standard way ${ }^{11}$. to give crude 4-acetamido-2,2,6,6-tetramethylpiperidin-1-oxyl. which was then hydrolyzed with potassium hydroxide, to give c:ude 4-amino-2.2.6.6-tetramethylpiperidin-1-oxyl. This was distilled in vacuo. and the fraction having b.p. 97-98\%/4 $\mathrm{mm} \mathrm{Hg}$ was obtained as hygroscopic needles in $72^{\circ}:$ yield, m.p. 32-34 ${ }^{\circ}$ (lit. ${ }^{2}$ m.p. $34-35^{\circ}$ ).

To a solution of 4-amino-2,2.6,6-tetramethylpiperidin-1-oxyl (3.75 mmol) in $5 \%$ sodium hydroxide $(15 \mathrm{~mL}$ ) 1 as added freshly distilled thiophosgene $(3.7 \mathrm{mmol}$ ) during $15 \mathrm{~min}$; the mixture was stired for $10 \mathrm{~min}$. and the orange precipitate resulting was filtered off, washed three times with cold water, and dried under vacuun over phosphorus peritzoxide. to give a red powder, m.p. $106-110^{\circ}$ (lit. ${ }^{16}$ m.p. $107-112^{\circ}$ ). in $65 \%$, yield.

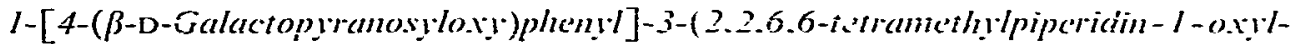

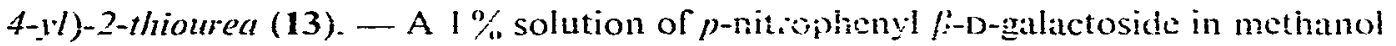
was hydrogenated in the presence of $10^{\circ} ;$ palladium-oil-charcoal at room temperature and atmospheric pressure, the suspension filtered, and the filtrate evalporated. to afford chromatographically pure $p$-aminophenyl $\beta$-1-galactopyranoside (t.l.c. in $1: 2$ chloroform-methanel, $\left.R_{\mathrm{F}} 0.8\right)$.

A solution of p-aminophenyl $/$-D-galactopyranoside $(0.14 \mathrm{~g}, 0.52 \mathrm{mmol})$ and 4-isothiocyanato-2.2.6.6-tetramethylpiperidin-1-oxyl $(0.11$ g. $0.52 \mathrm{mmol})$ in athanol $(30 \mathrm{~mL})$ was boiled for $1 \mathrm{~h}$ under reflux. The red solution was cvaporated to a syrun which was purified by column chromatography with $1: 1$ chlorofom-methinol as the eluant. The fractions having $R_{\mathrm{r}}-0.6$ vere combined. and evaporated to a syrup which, on trituration with ether. gave a light-orange solid in $65^{\prime \prime}$ " vield.

Anal. Calc. for $\mathrm{C}_{22} \mathrm{H}_{3}-\mathrm{N}_{3} \mathrm{O}, \mathrm{S} \cdot \mathrm{H}_{2} \mathrm{O}: \mathrm{C} .52 .47: \mathrm{H}, 7.22: \mathrm{N}, 8.32: \mathrm{S}, 6.38$. Found: $\mathrm{C}, 51.91 ; \mathrm{H}, 6.93 ; \mathrm{N}, 7.85: \mathrm{S}, 6.22$.

I-(Methy 2-deoxy-z-1)-ghucopl\%thosid-2-1\%)-3-(4-isothiocyanato-2.2,6.6-retra-

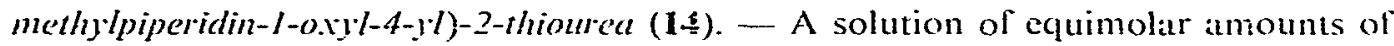
methyl 2-amino-2-deoxy-z-D-glucopyranoside and 4-isothiocyanato-2,2,6.6-tetramethylpiperidin-1-oxyl (0.3 mmol) in ethano! $(2.5 \mathrm{~mL})$ was boiled under reflux for $30 \mathrm{~min}$, to give a red solution that was evaporated to a syrup: this was purified by column chromatography with $9: 1$ dichloromethane-methanol as the eluant. The fractions having $R_{1} 0.7$ were combined. and evaporated to a red syrup which crystallized from ethanol-ether-petroleun eniner to yield analytically pure, ycllow crystaly in $57 \%$ yield; in.p. 190-192\%.

Ainal. Calc. for $\mathrm{C}_{17} \mathrm{H}_{32} \mathrm{~N}_{3} \mathrm{O}_{6} \mathrm{~S}: \mathrm{C}, 50.23: \mathrm{H}, 7.93: \mathrm{N}, 10.34 ; \mathrm{S} .7 .88$. Found: C, 50.27: H, 8.07; N, 10.22: S. 7.97.

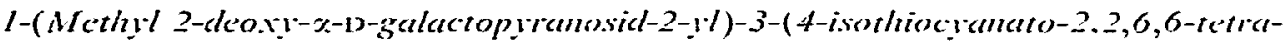
methylpiperidin-1-o.1./-4-1\%)-2-thiourca (15). - The procedure described for the synthesis of 14 was applied to yield compound 15 in $59 \%$ yield. as a light-orange solid from methanol-either. 
Anal. Calc. for $\mathrm{C}_{17} \mathrm{H}_{32} \mathrm{~N}_{3} \mathrm{O}_{6} \mathrm{~S}: \mathrm{C}, 50.23: \mathrm{H}, 7.93 ; \mathrm{N}, 10.34$. Found: $\mathrm{C}, 49.60 ;$ Fi. 7.84: N. 9.62.

Hydiol 1 sis of spin-labeled glycosides with $\varkappa_{-}$or $\beta$-D-galactosidase. - Coffee-

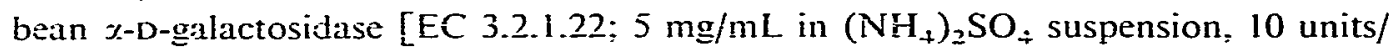
ing] was purchased from Boehringer-Mannheim. $\beta$-D-Galactosidase (bovine testicle, EC 3.2.1.23) was prepared by the method of Distler and Jourdian ${ }^{17}$. Digestions with galactosidase were conducted in a total volume of $0.2 \mathrm{~mL}$ containing $0.05 \mathrm{M}$ citrate, buffer, $\mathrm{pH} 4.3$ (for $\beta$-D-galactosidase) or $\mathrm{pH} 6.1$ (for $\alpha$-D-galactosidase), spin-labeled glycoside $(1 \mathrm{mg})$ - and 0.1 unit of $\beta$-D-galactosidase or 0.2 unit of $\pi$-D-galactosidase. Samples were incubated at $37^{\circ}$, and aliguots $(5 \mu \mathrm{L})$ were spotted from the reaction mixture onto t.l.c. plates at various time-intervals. Plates were developed with $9: 6: 3: 1$ butanol-acetic acid-ether-water, and the spots were detected by spraying with a solution containing aniline $(4 \mathrm{~mL})$. dipironylamine $(4 \mathrm{~g})$, acetone $(200 \mathrm{~mL})$, and $85^{\circ} . \mathrm{H}_{3} \mathrm{PO}_{\mp}(30 \mathrm{~mL})$. and heating for $10 \mathrm{~min}$ at $140^{\circ}$.

Hydrolysis of spin-labeled $\%-D$-galactosides was complete within a $12-h$ period of incubation. In the case of $\beta$-D-galactosides. the hydrolysis was incomplete using ß-D-galactosidase (bovine testicle). However, complete hydrolysis was achieved on using $\beta$-D-galactosidase (from Escherichia coli, Boehringer-Mannheim) by the procedure of Struve and NcConnell ${ }^{3}$.

\section{ACKNOWLEDCMENTS}

We thank Dr. Diane A. Blake of this laboratory for providing helpful assistance with the enzymic hydrolysis, as well as preparing $\beta$-D-galactosidase (bovine testicle). ${ }^{1} H$-N.m.r. spectra were kindly recorded by Dr. Y. Fouron of the University of Alberta. Edmonton, Alberta, Canada. This research was supported by U.S. Public Health grants AM-10171 and CA-20424.

\section{REFERENCES}

1 E. G. Rosantzev. in H. Ulrich (Translator and Ed.), Free Nitroxy/ Radicals, Plenum, London, 1970.

2 B. J. Gafiney, in L. J. Berginer (Ed.). Spin-Labeling. Theory and Applications, Academic Press, New York, 1976, p. 184.

3 W. G. Struie AND H. M. MCCoNivel, Biochem. Biopliss. Res. Commuth, 49 (1972) 1631-1637.

4 R. W. WIEN, J. D. MorristrT. ANd H. M. MCCONNELl. Biochemistry, 11 (1972) 3707-3715.

5 J. D. Apliv, D. E. Brooks, C. F. A. Clleivg, L. D. Hall, aNd P. E. Reid, Carbohydr. Res., 75 (1979) $11-16$.

6 .11. J. ADA tiv L. D. Hall. Carbohydr. Res., 68 (1979) c17-c20.

7 R. U. Leuteux, K. B. Heidriks, R. V. Stick. and K. JaMes, J. Am. Chem. Soc., 97 (1975) 4056-406?.

S C. P. J. Glaudelays a.d H. G. Fletcher, JR., Methods Carbohydr. Chem., 6 (1972) 373-376.

9 T. Ishikaty a.d H. G. Fleteher, JR., J. Org. Chem., 34 (1969) 563-571.

10 F. J. Krovzlr ayd C. SChuerch, Carbohydr. Res.. 33 (1974) 273-280.

11 Ref. 1. p. 214.

12 Ref. 1. p. 231.

13 R. U. Lemeux, Methots Carbohydr. Chem., 2 (1963) 221-222.

If R. IV. JEAilloz Aid P. J. Storry, Methods Carhohydr. Chem., 1 (1962) 224-225.

15 D. H. Braus.s, J. Am. Chem. Soc.. 51 (1929) 1820-1831.

16 Ref. 2, p. 215.

17 J. J. Distler and G. WV. Jourdiax, J. Biol. Chem., 248 (1973) 6772-6780. 